\title{
Apuntes de Derecho Registral (")
}

\author{
Por el Dr. JORGE AVENDAÑo VALDEZ, \\ Catedrático de Derecho Civil y de Práctica Registral.
}

\section{TITULO PRIMERO}

\section{LA PUBLICIDAD}

"Publicar" es hacer notorio o patente por voz de pregonero, o por otros medios, una cosa que se desea venga a noticia de todos. En otras palabras, es hacer algo patente o manifiesto al público. "Lo publico" es Io notorio, lo patente, lo manifiesto, lo que ven o lo saben todos. "Publicidad" es una calidad de lo público. El término, etimológicamente, viene del latín "publicus", que es hacer notorio, manifiesto.

La palabra publicidad, dice Jerónimo Gonzales (1), posee en el Derecho privado acepciones variadas que responden $\alpha$ un interés fundamental: el de llevar a conocimiento de los interesados actos o hechos jurídicos, reconocidos o apoyados por la ley con situaciones más o menos enérgicas. Unas veces es mera anuncio. Las notificaciones oficiales llegan a terceros para amparar la buena fé; otras, la publicidad es la categoría esencial de forma del acto jurídico.

A nosotros interesa un aspecto especial de la publicidad: la quo interviene en los actos jurídicos que crean, modifican y extinguen derechos sobte inmuebles. Restringida para tales fines, la publicidad consiste en

(x) El Dr. Jorga Avendaño Valdez, Catedrático de Derecho Civil $y$ de Práctica Rogistral; ha preparado estos "Apuntes de Derecho Registral" con el único objeto de que sirvan como guía para los alumnos que estudian la materia en nuestra Facultad. Cree en efecto, que el alumno necesita siempre un texto-guía que le permita estudiar el curso programado. La problemática y el desarrollo más o menos exhaustivo de las instituciones correspionde plantearlos en el dictado de la clase $y$ resolverlos con ol examon de las obras do consulta. - (N. de la R.).

(1) Jerónimo Gonzales, citado por Pascual Marín Pérez. (Introducción al Derecho hegiatzal (Madrid Editorial Merista de Derecho Privado). 
tornar conocidas ciertas situaciones jurídicas, especialmente cuando hay do por medio intereses de terceros. Esta finalidad tiene un doble aspecto, indica. Serpa Lopes (2); al mismo tiempo que la publicidad sirve de defensa. constituye un elemento de garantía.

En cuanto a la justificación de la publicidad en materia inmobiliaria, basta recordar que es característica del derecho real ser erga omnes, esto es, que se ejercita "contra todos". El derecho real, a diferencia del de crédito o personal, es absoluto en el sentido de que es oponible a todos. Digámoslo en otros términos, es un derecho de vigencia pública o social porque so realiza dentro de toda la colectividad. Pues bien, a fin de poder exigir de todos aquel respecto $y$ esa pasividad frente a mi derecho real, es obvio que esos "todos" deben estar en la posibilidad de enterarse, en cualquier momento y del modo más idóneo posible, de la vigencia del derecho que pretendo se respete. Por eso la publicidad es indispensable. Llega a ser requisito de fondo del derecho real. Veremos dspués que lamentablemente no siempre lo es. En muchas legislaciones -entre éstas, la nuestrala publicidad constituye una garantía, pero no es un requisito formal. Pero con prescindencia de la forma como se la reglamente, lo importante es precisar su razón de ser, es decir, su justificación.

EI Dr. Lizardo Alzamaro Silva (3) nos dice que, siendo la propiedad una concesión social ungida en derecho individual, su desplazamiento exige un exequátur que autorice esa transferencia y a la vez garantice que el derecho transferido es legítimo y que el interés público está amparado. Esteexequátur es la publicidad.

Quien compra un inmueble tiene que saber de quién es. Del mismo modo, tiene que saber qué clase de gravámenes pesan sobre él. En materia de bienes muebles el principio casi exclusivamente aceptado es que la posesión equivale al título. Es por lo tanto la tradición el medio común $y$ de ordinario suficiente de adquirir el dominio de dichos bienes. (Entre nosotros es así, según se desprende del artículo 890 del Código Civil). Pero tratóndose de inmuebles no se puede admitir la sola tradición. Es necesario aquel exequátur de orden social que constituye la publicidad.

Se nos presenta así la publicidad como una seguridad jurídica y una seguridad económica. Es lo primero porque cuando se opera la trasmisión - constitucićn de derechos reales sobre inmuebles, el adquiriente debe disponer de un medio para comprobar la existencia y calidad del derecho que se constituye o trasmite. De lo contrario, puede exponerse a sufrir la evicción de la $\cos \alpha$ que adquiera. $Y$ es también seguridad económica porque las operaciones sobre inmuebles exigen en la mayoría de los casos grandes inversiones de dinero que deben estar respaldadas por la publicidad.

Históricamente, hay autores que citan casos de publicidad en Grecia, sobretodo en materia de hipotecas. Parece que en las fachadas de los in-

(2) Miguel Marin de Serpa Loples, Tratado de Fegistros Públicos, Editoria a Nolte, voI. 1. 2a. edicao).

(3) Intardo Alzamora Silva, Ia Inseripción Inmobiliaria. Tesis para graduarse do Bachiller en Derecho. Lima, Libreria - Imprenta Gil, 1926). 
muebles se colocaban letreros con indicación del nombre del propietario $y$ de si estaba gravado o nó. Se cree que las ventas se anunciabon durante cinco días por un pregonero público. Se ha llegado a asegurar que mientras no se hacían estas proclamas la propiedad no quedaba trasmitida. Además, parece que en ciertos casos las ventas se efectuabon en presencia de un Magistrado o de tres vecinos honorables.

Fernando Campuzano (4), en contra de lo opinado por Cornil (5) y Tartufari (6), sostiene que en Roma no hubo clase alguna de publicidad de derecho, aún cuando admite que sí existió cierta publicidad de hecho. Así, se dieron la mancipatio y la injure cesio, que eran formas solemnes de trasmitir la propiedad, sobretodo de los res mancipi. En especial la in jure cesio importó cierta publicidad en la trasmisión de los bienes porque se reclizaba en presencia del Magistrado in jure). Sin embargo, en líneas generales puede decirse que en Roma fué la tradición el medis plenamente eficaz de trasmitir el dominio de las cosas.

Existieron también en Roma las llamadas "Tabulae", tablas que se colocaban en la parte frontal de los edificios en las que se consignaba el nombre del dueño. Aún cuando es cierto que los tabulae "no implicaron por sí la transferencia de la propiedad ni la constitución de la hipoteca, y no tuvieron otro valor que dar una simple noticia, desprovista de toda eficacia jurídica" (7), es evidente que constituyeron una expresión de publicidad de hecho.

Es realmente en el Derecho Germónico donde aparece la publicidad de derecho en materia inmobiliaria. Como anota Hedemann (8), el registro de la propiedad es una invención ajena a los romanos y de creación exclusivamente germana. Al aparecer la propiedad individual entre los germanos، su trasmisión se hizo de manera pública, recurriéndose en principio a un proceso judicial ficticio en algo análogo a la in jure cesio romana. Apareció la institución de la "gewere", constituída por actos en cuya virtud era trasmitido el señorío de los inmuebles. El término gewere significa "investidura" y revela este concepto: el adquirente de la cosa se "investía" con ella al verificarse la trasmisión. El concepto evolucionó hasta representar la exteriorización adecuada de la relación jurídica formalmente protegida por el derecho, lo que en verdad es ya una definición de publicidad. Dentro de la gewere se advierten dos extremos: todo derecho de dominio supone una exteriorización; y de otro lado, toda exteriorización implica efectos jurídicos que influyen sober el derecho mismo exteriorizado. Se daban pues dos momentos: el contrato real en primer término y luego la gewere propiamente dicha. Dentro de ésta, la investidura, y luego el abandono de la cosa por el enajenante, lo que se denominó "auflasung".

A partir del siglo XII se comenzó a consignar de oficio los negocios

(4) Femando Campuzano y Horma, Principlos Generales de Derecho Inmoblallario 1 Loglslaclón Hiponecaria. (Madrid, 1941, 2da. edición).

(5) Fornando Campuzano y Horma, obra cltada.

(6) Fernando Campurano y Horma, obra citada.

(7) Fernando Campuzano Y Horma, obra citada.

(B) Pascual Marín Pérez, obra citada. 
referentes $\alpha$ inmuebles en libros públicos. Se explica esto en primer término, por una razón de seguridad: las partes estaban facultadas para solicitar un testimonio ("notitia") que contenía copia del proceso ficto a que antes nos hemos referido. De otro lado, había de por medio un interés fiscal de conocer los nombres de los propietarios y la situación verdadera de los inmuebles de la localidad.

Fué así como nació la institución del registro de la propiedad inmueble. Las inscripciones de dominio, en principio mezcladas con asuntos de orden administrativo y sumamente defectuosas, se fueron perfeccionando $Y$ el orden de los inmuebles en los libros, que al principio fué cronológico, varió sustancialmente hacia la formación del folio real. En un capítulo posterior haremos el exámen del actual sistema inmobiliario alemán.

En el derecho moderno, el término publicidad, entendido como el principio que constituye el eje de los sistemas registrales, abarca un doble aspecto que es necesario estudiar: el de la legitimación registral y el de la fé pública del registro.

So expresa con legitimación rogistral que los derechos y situaciones reales sobre inmuebles, por el hecho de su incorporación al registro, es decir, por el hecho de hacerse públicas, una vez cumplidas las exigencias de Ley, quedan adscritos $a$ su titular con una investidura de legitimidad que el registro ampara frente a todos. La publicidad absorbe asi cualquier vicio que pudiera tener el título y lo convalida. La publicidad redime las deficiencias del derecho $\mathrm{y}$ lo hace perfecto.

Pero la legitimación no es suficiente $y$ por lo tanto se sanciona el principio de la fé pública del reglstro. Quien adquirió de buena fé y a título oneroso, de quien en el Registro aparece como dueño, $\theta$ inscribe el derecho adquirido, está protegido erga omnes. No importa que el enajenante no fuera en verdad dueño. Pudo haber vendido antes su derecho. Pero si ésta transferencia no consta en el Registro, la posterior que se inscribe y que ve verificó a título oneroso, mantiene todo su valor.

La legitimación registral se refiere al título, al derecho que inviste al titular. El solo hecho de que este derecho ingrese al Registro y sea sometido a la publicidad que dicho Registro realiza, legitima el título, lo hace perfectamente válido y los defectos de fondo y forma que pudiera tener quedan automáticamente saneados, por el mérito de la publicidad. En cambio la fé pública del Registro es un efecto en relación a los terceros, no ya al título mismo. Su origen es el mismo: la publicidad. Pero va dirigido al adquirente que confía y acepta lo que el Registro dice.

Esta publciidad sustantiva, que como hemos visto comprende la legi-

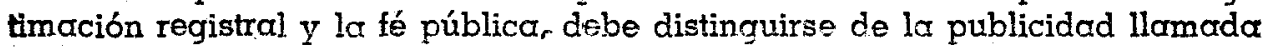
adjetiva. Debemos entender por esta última la posibilidad de que el público se entere del contenido de los libros en los que aparecen inscritos los derechos reales sobre inmuebles. Esto se realiza, generalmente, mediante el exómen directo de los libros por los interesados y a través de las certificaciones que la institución registral expide. En síntesis, la publicidad adjetiva realiza, actualiza y hace posible la publicidad sustantiva.

Se distingue también entre publicidad constitutiva y declarativa. La primera se considera sustancialmente indispensable para la constitución de 
un determinado derecho real. Tal ocurre con la adquisición de la propiedad en Alemania y con la constitución de la hipoteca entre nosotros. En estos casos la publicidad tiene el carácter de constitutiva porque sin ella no se ha trasmitido la propiedad ni ha nacido la hipoteca, respectivamente. En cambio, la publicidad es sólo declarativa cuando se refiere a actos o contratos ya perfectos y cuya falta da lugar a ciertos pequeños efectos que en ningún caso invalidom el acto o contrato previo, que era perfecto desde antes de gozar de la publicidad. Tal es el caso, por ejemplo, de la trasmisión de la propiedad inmueble en el Perú, la que se realiza, según lo dispuesto en el artículo 1172 del Código Civil, medionte el simple consentimiento. El contrato de compra venta es, por ejemplo, suficiente para trasmitir la propiedad inmobiliaria. En cuanto existe acuerdo en cosa y precio, la propiedad se ha trasmitido válidamente. La posterior inscripción de ese contrato en el Registro no hace mejor la transferencia en cuonto a ella y a los intervinientes respecta. La situación jurídica estaba constituída desde antes de ingresar al Registro; éste no hará sino declarar lo ya existente.

A propósito de la trasmisión de la propiedad inmobiliaria, conviene recordar que existen en ella dos momentos: el de obligarse, de carácter privado, y el de adquirir, de tipo público. El título es fundamento del primero; el modo de adquirir lo es del segundo. Zaccarie (9) define el título como la"ccusa jurídica", y el modo de adquirir como "el hecho" mediante el cual se consuma la adquisición real. En Roma estos dos momentos estuvieron diferenciados. Bástanos recordar que el contrato de compra-venta no trasmitía la propiedad sino simplemente originaba la obligación de entregar la cosa. Era la tradición la que en buena cuenta determinaba la trasmisión del dominio. En Roma, en consecuencia, el título era el contrato; el modo de adquirir la tradición. En Alemania, donde se cree. vulgarmente que la inscripción lo es todo, el convenio particular es insuficiente pero al mismo tiempo requisito indispensable de la posterior inscripción, que viene a ser la última parte de un ciclo lógico que realiza, erga omnes, la trasmisión de la propiedad. No ha desaparecido pues en el Derecho moderno la romana distinción entre título y modo de adquirir.

Hoy, sin embargo, la tradición ha sido sustituída por otro hecho que reviste mayores caracteres de publicidad. Se trata de la inscripción en el Registro de la Propiedad Inmueble. Así, las garantías de los terceros y de las mismas partes en el convenio son mayores. Así, desaparecen la clandestinidad $y$ el traude. Por esto legislaciones avanzadas señalan ambos momentos -el contrato y la inscripción- como requisitos indispensables los dos para la institución de los derechas reales. Dan así a la publicidad, efectuada mediante la institución del Registro Inmobiliario, el carácter de constitutiva a que nos referíamos líneas arriba.

(9) Lizardo Alzamora Silva, obra citada. 


\section{TITULO SEGUNDO}

\section{El REGISTRO INMOBIIARIO. - PRINCIPALES SISTEMAS}

De las muchas definiciones que se han dado del Registro de la Propiedad Inmueble, que se denomina genéricamente Registro Inmobilia. rio, una de las más completas es la de Gimenez Arnau (10): "es el organismo técnico de carácter público, encargado de notificar a la sociedad y hacer más eficaz, o plenamente eficaz, la modificación, constitución y extinción de derechos reales sobre bienes inmuebles".

Se trata, en primer término, de un organismo técnico. Esto es, conducido por especialistas en Derecho (examen de los títulos), en Topografía y Agrimensura (estudio de la realidad física de los inmuebles). Es, además, un organismo público. Lo es porque su finalidad es eminentemente pública: el Registro cautela los intereses del titular del derecho y los de todos los miembros de la colectividad. El Registro, además, procura al Fisco una noción detallada de la situación jurídica de los inmuebles. El Registro notifica a la sociedad, continúa la definición. Efectivamente, la publicidad se realiza mediante notificación. No se trata, desde luego, de una notificación personal a cada uno de los integrantes de la colectividad. La sola existencia del Registro y la posibilidad de que los interesados acudan a él a enterarse de los asientos de dominio, es esa notificación a que se refiere acertadarmente Gimenez Arnau. La institución, concluye la definición, "hace más eficaz, o plenamente eficaz, la constitución, modificación o extinción de los derechos reales sobre inmuebles". El ideal es que la eficacia que se logre sea plena. Muchas veces no lo es. Precisamente en esto radica la diferencia entre publicidad constitutiva y declarativa, ya comentada.

Concebido así el Registro de la Propiedad Inmueble, veamos cuáles son los fines principales que persigue esta institución:

1) dar a conocer el verdadero estado de la propiedad inmueble, haciendo constar de manera pública la historia del dominio de los bienes;

2) asentar sobre bases sólidas el crédito territorial;

3) impedir los fraudes en las enajenaciones y constitución de gravámenes sobre inmuebles;

4) dar a conocer a los que intervienen en la contratación sobre inmuebles una firme garantía para la efectividad de su derecho.

Examinemos cada uno de estos fines.

1) La historia del dominio de los inmuebles consta claramente en los sistemas en los que cada bien tiene destinada una hoja del Libro-registro. Antiguamente, las inscripciones se hacían por orden cronológico; se hicieron támbién por los nombres de los titulares de los derechos. Posteriormente se

(10) Ignacio de Casso y Romero y Francisco Cervera y Jiménez Alfaro, Dicclonario de Derecho Privado. (Editorial Labor S.A., 1950). 
advirtió que la manera más eficaz de dar una noción clara de la situación jurídica del inmueble era reservando $\alpha$ cada uno de éstos un espacio especial dentro del libro, denominado 'hoja" (si bien pueden ser varias, se emplea el término en singular con propósito genérico). Se anota la primera inscripción de dominio y luego a continuación las sucesivas transferencias de ese bien y la constitución de gravámenes sobre él. Así, el último asiento es demostrativo de la situación actual. Anexo a este libro se crearon índices, del tipo personal, en los que resulta fócil encontrar los nombres de los titulares de los derechos.

2) El Registro inmobiliario asegura $y$ fomenta el crédito territorial. Difícilmente puede animarse persona alguna a prestar dinero con garantía inmobiliaria si no conoce con exactitud y certeza la persona del propietario y los gravómenes que afectan el bien. Antiguamente, con las hipotecas ocultas, era frecuente el engaño y difícilmente había quien contratara empréstitos con garantía hipotecaria.

3) Consecuencia de lo anterior es que el Registro persiga impedir los fraudes. Dentro de un sistema registral perfecto no debe admitirse la posibilidad de vender lo ajeno en materia de inmuebles. Podría ocurrir sólo mediando error o mala fé de los funcionarios del Registro. Pero como esto no puede presumirse, sino al contrario debe creerse en la honradez $\Psi$ capacidad de los funcionarios del Registro, debe rechazarse de plano repetimos, la posibilidad de vender inmuebles ajenos.

4) Por último, persigue el Registro que el tituiar tenga una firme garantía sobre la efectividad de su derecho. No se trata de garantizar solamente a los terceros -involucrando dentro de este término a todos menos los intervinientes en el contrato- sino también a éstos. El adquirente necesita poder acreditar fehacientemente su derecho $\mathrm{y}$ al mismo tiempo estar seguro de que éste es sancionado públicamente y por tanto efectivo erga omnes.

Se han hecho variadas clasificaciones de los ordenamientos jurídicos inmobiliarios. Podríamos reducir a tres los sistemas relativos a la organlzación de la propiedad inmueble:

19) Sistema de la clandestinidad. Impera en Francia, donde se da un predominio casi absoluto al título, a la obligación de entregar. Se trata evidentemente de un ordenamiento espiritualista. El Registro es un elemento que no produce efecto alguno en la trasmisión del derecho.

$2^{\circ}$ ) Sistema de la matriculación. Tiene vigencia en Alemania y en los Páses Bajos el imperio del Acta Torrens, o Sistema Torrens de registro Fl modo de adquirir, representado por la inscripción en el Registro de la Propiedad, es constitutivo en la trasmisión de la propiedad. No debe olvidarse, sin embargo, que aún cuando la inscripción es determinante, no puede prescindirse del consentimiento o vínculo inter-partes, requisito sin el cual es imposible verificar la inscripción a favor del nuevo propietario.

3?) Sistema mixto. Participa de los dos anteriores. El consentimiento produce la transferencia del dominio pero con efectos solamente entre las partes. La inscripción del acto tiene efectos para los terceros. Este sistema mixto rige en España y entre nosotros.

Estudiaremos los sistemas francés, alemán $Y$ Torrens, dejando para un capítulo posterior el examen del nuestro. 
Sistema francés de la propledad inmobiliaria. - Según el derecho civil francés, entre los contratantes la propiedad se trasmite por el solo consentimiento, sin que sea necesaria la tradición ni la inscripción del acto. Con relación a terceros, se distingue si la enajenación se realiza a título gratuito $u$ oneroso. En el primer supuesto es necesaria la inscripción, no así en el segundo.

En síntesis, en Francia la propiedad inmobiliaria se trasmite, entre los contratantes y con relación a terceros, por el solo consentimiento. Salvo que se trate de una trasmisión a título gratuito, la cual, para que tenga efectos respecto de terceros, debe ingresar al registro.

Trascurridos cincuenta años de la dación del Código Civil francés, con fecha 23 de marzo de 1855, se promulgó la ley del registro inmobiliario, con miras de modificar el sistema que había creado la legislación civil.

Según esta ley, el sistema trancés es de trascripción y no de inscripción. Esta trascripción, que consiste en la copia literal del título en el libroregistro, se verifica por el mérito de instrumentos auténticbs, aún privados y se distingue de la inscripción en que ésta no supone la copia literal del título en el libro sino tan sólo el asentamiento de un extracto del mismo. Como es obvio, el sistema de la trascripción es primitivo, y por eso ha sido abandonado. La copia íntegra del acto se traduce en errores, en retardos y en consignar circunstancias individuales que conciernen únicamente a los interesados $\mathrm{y}$, por lo mismo, extrañas al interés público perseguido con la transcripción (este sistema de trascripción se modificó por la ley de 24 de julio de 1921, la cual lo sustituyó por el de inscripción).

Posteriormente, por decreto-ley de 30 de octubre de 1935, se modificó aún más el sistema registral francés. Lamentablemente los medios informativos sobre el alcance de esta reforma son precarios, por lo que nos resulta imposible pronunciarnos sobre ella. En esta virtud, continuaremos examinando el sistema francés a la luz de la ley originaria de 1855.

En lo que se refiere a la organización de los libros, ellos son de tipo personal. No existe, por consiguiente, en Francia el llamado folio real o sistema en el cual cada inmueble tiene destinada una hoja o partida diferente. En Francia los actos o contratos sobre inmuebles se asientan en el libro-registro por los nombres de los intervinientes y según orden cronológico. Esta sola circunstancia nos revela hasta qué punto es ineficaz el sistema trancés. Para conocer la historia del dominio de un inmueble determinado, es preciso conocer los nombres de los diversos propietarios del mismo.

Está demás decir que en Francia la inscripción no legitima el título. Dentro del Registro pueden existir, y de hecho existen, títulos viciados. Por otra parte, no rige el principio llamado del "tracto sucesivo", según el cual para inscribir un acto o contrato es necesario que previamente esté inscrito el derecho de donde emana la trasmisión o gravámen. Es éste un principio que informa prácticamente todos los sistemas registrales modernos. Inclusive el nuestro lo exhibe consagrado por el artículo 1045 del Código Civil. Su razón de ser es simple: garantiza la continuidad en la historia del dominio que permitirá a quien estudie la titulación saber si ésta es firme o nó a lo largo de los 30 años de la prescripción adquisttiva. 
Las críticas que se puedan formular a este sistema fluyen de la comparación que se haga con los que a continuación comentamos.

Sistema alemán.-Está organizado bajo el folio real. Para cada finca se reserva "una hoja". Existen dos libros: el Flurbuch, que es un catastro perfecto y que representa el elemento físico de los inmuebles. En él se encuentra la descripción del bien, su topografía, linderos, órea, naturaleza, etc., $y$ el Grünbuch, que es el registro legal, en el que corren inscritos los derechos sobre inmuebles.

Dentro del sistema alemán es preciso distinguir entre la inscripción del derecho y la inscripción de hechos, L $\alpha$ primera se refiere, tal como su nombre lo indica, al derecho que inviste al titular. Esta inscripción la cubre en forma absoluta el registro en Alemania. En otras palabras, garantiza plenamente que tal persona es titular de cual derecho sobre determinado bien. Los hechos, las expresiones accidentales de la finca, tales como su situación, área o medidas perimétricas, no se encuentran garantidos.

La inscripción en Alemania tiene el carácter de constitutiva. Es interesante anotar que a diferencia de lo que sucede on Francia, donde el solo conseniimiento produce la trasmisión de la propiedad, en Alemania el solo consentimiento es insuficiente, aún entre las partes intervinientes en el acto. Se distingue claramente entre el acuerdo o convenio de las partes y la posterior inscripción de la transferencia del dominio.

En Alemania la inscripción es obligatoria. La matriculación o ingreso de un bien al Registro, se realiza de oficio. En cambio las posteriores transferencias o gravámenes se inscriben siempre a instancia de parte.

El principio del tracto sucesivo rige plenamente.

El Registro no sólo califica la autenticidad y la fuerza probatoria de la solicitud en demanda del asiento y de los títulos que la acompañan, sino que puede intervenir de oficio avisando a los interesados, haciendo anotaciones preventivas, etc. Consecuencia de estos amplios poderes de la ins. titución registral, son dos: $1^{\circ}$ que el título queda perfeccionado por su ingreso al Registro (rige plenamente la legitimación registral) y $2^{\circ}$ que el valor probatorio del esiento de dominio es absoluto e indiscutible.

Sistema Torrens. - Fué concebido y llevado a la próctica por Sir Robert Torrens en 1858. El sistema es de inscripción y no de trascripción. Cada inmueble cuenta con un espacio determinado, evitóndose de este modo las deficiencias que resultan de la organización personal de los libros.

Es interesante anotar que la inscripción no es siempre obligatoria como es en Alemania. Es obligatoria tratándose de tierras que han sido concedidas por el Estado a los particulares con posterioridad a la promulgación de la ley creadora del Acta Torrens. Sin embargo, son tantas las ventajas que se obtienen con la inscripción que en la práctica la mayoría de los propietarios recurren a ella.

El procedimiento para lograr la matriculación, o ingreso de un bien al Registro, es, a grandes rasgos, el siguiente: el propietario lo solicita por escrito acompañando los títulos que posea, antecedentes, planos y descripción del inmueble. Estos documentos son examinados por especialistas; quie$n \in s$ pueden opinar por el rechazo inmediato, el mismo que puede contradecirse ante los Tribunales de Justicia. Si por el contrario la titulación es 
correcta, pasa el expediente al examen de los topógrafos quienes estudian el plano presentado. A continuación se publican avisos con el fin de provocar oposiciones de terceros a quienes la matriculación pudiera perjudicar. El término para deducir oposiciones es de un mes. La autoridad judicial es la encargada de resolverlas en caso de que se produzcan. Si no hay oposición alguna, se hace la matriculación del inmueble, expidiéndose el certificado de propiedad a nombre del interesado. Este certificado acredita plenamente el dominio y reemplaza definitivamente los antecedentes del mismo. En una palabra, el certificado es el título de propiedad.

Las transferencias del inmueble se producen de manera sencilla: basta exhibir el certificado expedido por el Registro para acreditar fehacientemente el derecho de propiedad. El contrato se realiza ante un testigo y puede redactarse en un formulario especial o simplemente al dorso del mismo certificado.El nuevo dueño remite el certificado y el contrato al Registro $\mathrm{Y}$ éste emite un certificado nuevo a nombre del adquirente.

El fundamento de este sistema radica en Ia inatacabilidad del título. El Estado se responsabiliza de la legitimidad de los títulos que otorga. Para cubrir la garantía de esta legitimidad, la ley dispone la creación de un fondo especial constituído por los derechos especiales que al efecto se cobran. Este fondo se destina $\alpha$ indemnizar $\alpha$ quienes resultaren perjudicados por la expedición de un certificado.

\section{TITULO TERCERO}

\section{EL REGISTRO DE LA PROPIEDAD INMUEBLE EN EL PERU.}

Razones de falta de espacio y tiempo nos impiden desarrollar este tema con la amplitud deseada. Nos hemos de circunscribir, por consiguiente, al examen de los siguientes puntos:

a) Disposiciones legales aplicables al Registro,

b) Organización de los libros.

c) Actos inscribibles,

d) Matriculación de un inmueble,

e) Inscripciones sucesivas respecto de un bien ya matriculado, concepto de título para los efectos registrales:

f) Publicidad adjetiva: 1) examen de los libros $y$ 2) certificados que expide el Registro; $y$

g) Efectos de las inscripciones.

a) Disposiciones legales aplicables al Registro.-Dos son las principales fuentes legales de la institución entre nosotros: el Código Civil (artículo 1036 al 1052) y el Reglamento de las Inscripciones. Aquel no exige comentario alguno. Los artículos 1036 al 1052 serán examinados a lo largo de este título. En cambio el Reglamento de las Inscripciones sí presenta 
algunos problemas que precisa examinar. El principal de ellos es el de su orígen, lo que equivale a decir el de su validez legal.

El Reglamento de las Inscripciones fué formulado por la Junta de Vigilancia de los Registros Públicos y aprobado por la Corte Suprema de la República en acuerdo de 17 de diciembre de 1936. Digamos una palabra sobre lo que es la Junta de Vigilancia. De conformidad con lo dispuesto en el cortículo 1038 del Código Civil, los Registros (debe entenderse por Registros, el de Propiedad, de Personas Jurídicas, de Mandatos, etc.- ver art. 1036) están bajo la dirección de la Junta de Vigilancia, la cual está integrada por el Ministro de Justicia, uno de los Fiscales en lo civil de la Corte Supiema designado por ella, el Decano de la Facultad de Derecho de la Universidad Nacional Mayor de San Marcos, el Decano del Colegio de Abogados $y$ el Director del Registro. La Junta de Vigilancia es, en consecuencia, un organismo colegiado encargado de la fiscalización y control de los Registros. Púes bien, la Junta de Vigilancia elaboró el Reglamento de las Inscripciones y luego lo sometió a la aprobación de la Corte Suprema de la República, quien se la otorgó con fecha 17 de diciembre de 1936.

¿Esta aprobación de la Corte Suprema ha dado fuerza de ley al Reglamento? En principo la respuesta es negativa. Como sabemos, tienen fuerza legal, en primer lugar, las disposiciones emanadas del Congreso constituído con arreglo a ley; y también las que dicta el Poder Ejecutivo para ciertas materias y en determinados casos. Tales, los Decretos y Resoluciones Supremas, etc. El Reglamento aprobado por la Corte Suprema no emanó del Parlamento ni del Ejecutivo. Al parecer, carecería de vigencia legal.

Sin embargo, quienes sostienen lo contrario, es decir que el Reglamento tiene validez legal, se apoyan en lo dispuesto por el artículo 1039 del Código Civil, el cual dispone textualmente que la Junta de Vigilancia "... dictará los reglamentos del caso, sometiendo a la Corte Suprema, para su aprobación, los que no sean de orden meramente interno". El Código Civil habría, pues, establecido el procedimiento a seguir para el caso concreto del Reglamento de las Inscripciones, otorgando así a éste plena validez legal.

b) Organización de los libros.-1) Rige entre nosotros el llamado "folio real", que ya hemos examinado anteriormente, por lo que resulta innecesario repetir su concepto. El principio está consagrado en el artículo $18^{\circ}$ del Reglamento de las Inscripciones, que dispone que todas las inscripciones posteriores se extenderán $\alpha$ continuación del primer asiento por orden sucesivo sin dejar claros entre uno $\mathrm{y}$ otro asiento.

Además del libro "Registro de Propiedad" (ver art. 13 $3^{\circ}$ del Reglamento), que está organizado por fincas o inmuebles conforme hemos visto, existen índices, que son libros auxiliares. El artículo $34^{\circ}$ del Reglomento dispone que es facultad de la Junta de Vigilancia fijar el número de estos índices. En efecto, la Junta ha acordado que deben llevarse dos índices de propiedad, uno por personas y otro por inmuebles.

Estos índices permiten saber qué inmuebles aparecen inscritos $a$ nombre de determinada persona $y$, además, en qué tomo y folio está regis'trado tal o cual inmueble cuya titulación se desea examinar.

2) Rige entre nosotros el sistema de "inscripción" y no el de "tras- 
cripción". Esto es, el Registrador debe asentar en el libro un resúmen o extracto del acto o contrato cuya inscripción se ha solicitado. Este resúmen. debe contener, $a$ tenor de lo dispuesto en el artículo 1048 del Código Civil. los nombres y estado civil de los interesados, la situación del inmueble y su extensión y valor. El artículo $44^{\circ}$ del Reglamento de las Inscripciones es más explícito y contiene una enumeración detallada de las indicaciones que debe contener toda inscripción.

3) Rige, por último, entre nosotros el principio llamado del "tracto sucesivo" o de "continuidad", al cual también hemos tenido oportunidad de referimos anteriormente. Este principio está consagrado en el artículo 1045 del Código Civil, según el cual para inscribir un acto o contrato es preciso que esté inscrito o se inscriba el derecho de donde emana ese contrato. En virtud de esta disposición es posible contar en cada partida del Registro con una verdadera historia del dominio del inmueble. El examen de esta "historia" resulta indispensable para saber si la titulación es firme - nó, para poder sumar las posesiones al amparo del artículo 829 del Código Civil hasta completar los 30 años de la usucapión.

c).-Actos inscribibles-El-artículo 1042 del Código Civil enumera los actos inscribibles en el registro del departamento o provincia donde está ubicado el inmueble. $Y$ el artículo 1043 del mismo Código, disponø que el reglamento (se refiere al Reglamento de las Inscripciones) indicará los casos en que los actos a que se refiere el artículo anterior serón materia de simple anotación. Es preciso, pues, antes de examinar el artículo 1042, distinguir entre inscripción y anotación. Aquella se da en la generalidad de los casos. Lo normal es que un acto se inscriba. $Y$ cuando tal ocurre, se producen los efectos que luego estudiaremos como producidos por las inscripciones. Excepcionalmente, sin embargo, determinados actos simplemente se anotan. El artículo $79^{\circ}$ del Reglamento de las Inscripciones se ocupa de la materia. Dice que las anotaciones a que se refiere el artículo 1043 del C.C. se denominarón preventivas, y son materia de ellas los siguientes actos:

(a) Ios embargos preventivos y definitivos.-I.a distinción entre estas dos medidas es materia de otro curso por lo que no nos corresponde hacerla.

(b) Iras døtmandas, a juicio ciel Jriez. Respecto de esto conviene detenerse un poco. ¿Qué clase de demandas son objeto de anotación? ¿Acaso podrá anotarse una demanda ejecutiva por ejemplo? La respuesta es no. Deberón anotarse solamente aquellas demandas que versan directamente sobre inmuebles. Por ejemplo, demandas de reivindicación, de constitución de servidumbres, de declaración de usucapión, etc. En la próctica, los Jueces se han mostrado demasiado liberales en esta materia. Generalmente han dispuesto la anotación preventiva de demandas que no porcedía legalmente anotar. Como vemos luego, los efectos de las anotaciones son casi tan graves como los de una inscripción, por lo que, en la práctica, la anotación preventiva de una demanda importa un gravámen. Y si lo comparamos con un embargo preventivo, por ejemplo, resulta más oneroso que éste, ya que mientras que el embargo preventivo puede levantarse con una fian- 
za suficiente a juicio del Juez, la anotación de la demanda no puede cancelarse con una fianza.

(c) Son también objeto de anotación preventiva, continúa el artículo $79^{\circ}$ del Reglamento en sus incisos $3^{\circ}$ Y $4^{\circ}$, los títulos que no pueden inscribirse porque adolecen de una falta subsanable 0 porque no está inscrito el derecho de donde emana la trasmisión o gravámen. Es obvio que en estos casos las anotaciones preventivas tienen el carácter de temporales, y así lo establece el artículo $92^{\circ}$ del mismo Reglamento. En cambio las anotaciones preventivas practicadas por orden judicial no son temporales (art. 97\%).

Veamos ahora cuáles actos son inscribibles. Como ya hemos indicado, se ocupa de esta materia el artículo 1042 del Código Civil.

(1) El inciso primero comprende prócticamente toda clase de actos y contratos sobre inmuebles. Hubiera bastado que el lesgislador pusiera este inciso. Los nueve restantes son en buena cuenta casos específicos ya previstos en la fórmula genérica del inciso primero.

(2) No necesito explicarles qué son las promesas de venta. Ustedes conocen la materia del curso de Contratos. Basta indicar que a ellas se refiere el artículo 1392 del Código Civil.

(3) Tampoco debo explicarles lo que son los derechos de retroventa. $\mathrm{Me}$ remito $\alpha$ los conocimientos adquiridos en el curso de Contratos y a lo dispuesto en el crtículo 1431 y ss. del C. C.

(4) El inc. $4^{\circ}$ se refiere al cumplimiento total o parcial de los actos registrados o de las condiciones de que ellos dependen. $\mathrm{Si}$, por ejemplo, estuviera registrada una hipoteca sobre determinado inmueble, constituída en garantía del pago de un saldo de precio, y el obligado cumpliera con pagar este saldo de precio, total o parcialmente, procedería inscribir esta cancelación total o parcial, levantando la hipoteca, también total o parcialmente. $\bar{A}$ casos como éste se refiere el inciso $4^{\circ}$. La última parte menciona la inscripción de "las condiciones de que ellos dependen". Puede ocurrir que el cumplimiento o la existencia de un determinado acto dependa de condición suspensiva o resolutoria, respectivamente. En ambos casos, procederá inscribir no solamente el acto o contrato sino también la condición mima para darle publicidad.

(5) El inciso quinto se refiere a las restricciones o limitaciones de la propiedad, derivadas de los contratos, testamentos y sentencias. Compréndese dentro de estas limitaciones, por ejemplo, las servidumbres. Podría incluirse también los derechos de usufructo, uso y habitación, que si bien no son limitaciones de la propiedad sino desmembraciones del dominio, importan en la práctica verdaderas restricciones en las facultades del propietario.

(6) Por protestas de hipoteca debe entenderse la promesa de constituir hipoteca. Es ésta una promesa formal, constante de instrumento público, que se registra en la partida de inscripción del inmueble que se va a gravar en garantía de determinada obligación.

(7) El inciso sétimo se refiere a los embargos; los cuales son materia de anotación preventiva conforme hemos visto.

(8) Lo mismo rige respecto de las demandas.

(9) El inciso noveno se refiere a los contratos de arrendamiento, que 
no son derechos reales sino personales o de crédito, pero que importar. utilización del bien. Cuando estos contratos recaen sobre inmuebles, pueden inscribirse $y$ de esta inscripción se derivan efectos importantes.

(10) El último inciso del artículo se refiere a las autorizaciones judiciales que permitan practicar actos inscribibles sobre el inmueble. En esto caso se registra el mandato judicial en que consta la autorización.

d) Matriculación de un inmueble.-Por matriculación de un inmueble en el Registro debe entenderse su ingreso a los libros. Es lo que se conoce con el nombre de primera inscripción de dominio.

Como sabemos, en el Perú la inscripción no es obligatoria sino facultativa. El Anuario Estadístico del Perú correspondiente al año 1953 informó que habían 83,264 predios inscritos en el Perú, comprendiendo tanto los rústicos como los urbanos. La Superintendencia de Contribuciones giró, en e laño 1954, 136,850 recibos por concepto del impuesto de predios. Este criterio no es muy exacto para conocer cuántos predios hay en el Perú porque, por ejemplo, el sub-arriendo está gravado con el impuesto de predios, lo que revela que un inmueble puede estar afecto dos veces a dicho impuesto, pero aún así la cifra puede valer como un índice. Según estos datos apenas el $60 \%$ de los inmuebles están matriculados.

Dijimos que en el Perú la inscripción no es obligatoria. Esta regla sufre dos únicas excepciones en el caso de la hipoteca y del hogar de familia. Según lo dispuesto en los artículos 1013 y 467 del Código Civil, la inscripción es obligatoria cuando se trata de las mencionadas instituciones. En consecuencia, en estos casos la inscripción tiene el carácter de constitutiva; sin inscripción no hay hipoteca ni hogar de familia.

De acuerdo con lo dispuesto en el artículo 1046 del Código Civil, la matriculación 0 ingreso de un inmueble al Registro, se produce de una de estas maneras: presentándose títulos de dominio con una antigüiedad de veinte años $o$, en su defecto, títulos supletorios. Como sabemos, los "títulos" están constituídos por los documentos en que constan los actos jurídicos relativos al bien durante los últimos veinte años. Estos actos deben ser ininterrumpidos. Lo que interesa es examinar la validez de las sucesivas transferencias para que proceda la suma de las posesiones a que se refiero el artículo 829 del Código Civil, hasta alcanzar los treinta años de la prescripción larga $\mathrm{y}$ de este modo acreditar el dominio. Siendo esto así, no se comprende por qué el legislador ha consignado veinte años y no treinta en el artículo 1046. Si lo que interesa es acreditar la propiedad, para que la primera de dominio se inscriba en favor de quien realmente es dueño, no se comprende por qué se exigen títulos con una antigriedad de 20 años cuando el plazo de prescripción es 30 .

Si no hubieran títulos, bien sea porque se han extraviado y es imposible obtener duplicados o porque nunca se extendieron documentos comprobativos de las transferencias, el propietario deberá formar títulos supletorios de conformidad con lo dispuesto en el Código de Procedimientos Civiles. El expediente de títulos supletorios amerita para la primera inscripción de dominio. 
e) Inscripciones sucesivas respecto de un bien ya matriculado. Dispone el artículo $4^{\circ}$ del Reglomento que las inscripciones se extenderán por el mérito de títulos que consten por instrumento público. A continuación, el artículo $5^{\circ}$ del mismo Reglamento define lo que se entiende por título: es el instrumento público en que funda su derecho la persona a cuyo favor ha de practicarse la inscripción. Así, es título para los efectos registrales el testimonio en que consta la compra-venta, la constitución de hipoteca, el arrendamiento, la constitución de servidumbre, etc.

Como se advierte, el Reglamento confunde el concepto de "título" con el del documento en que consta el título. Porque en verdad el título es un acto jurídico. Es la compra-venta misma; es el acto mismo en que nace el usufructo, etc. Este título o acto jurídico viene representando o acreditado por un instrumento, que ha de ser público, y así amerita para inscribirse en el Registro.

En têrminos registrales, se conoce con el nombre de "parte" los documentos en que consta el título. Son las partes los que el Notario presenta al Registro para que se inscriba determinado acto. Hablamos en plural porque según el artículo $30^{\circ}$ del Reglamento, los títulos deben ingresar por duplicado. Un ejemplar permanece archivado en la oficina del Registro. El otro es devuelto al interesado con una constancia al pie, extendida por el Registrador, que acredite que el acto ha merecido inscripción. (Ärtículo 31\%).

De conformidad con lo dispuesto en el artículo 1044 del Código Civil, el Registrador debe apreciar la legalidad del título. La ley le confiere la calidad de Juez de Títulos y lo faculta para discernir si el título (acto jurídico) está o no arreglado a ley $\mathrm{y}$. por consiguiente, si debe ingresar al Registro o nó.

El Registrador puede, pues, tachar un título y denegar su inscripción. En este caso, al amparo de lo dispuesto en el artículo 240 del Reglamento de las Inscripciones, los interesados pueden interponer, contra la tacha, recurso de revisión por ante el Director General de los Registros Públicos. Contrariamente a lo que ocurre generalmente, en que el recurso impugnatorio se interpone ante el funcionario que ha expedido la resolución que se impugna, en este caso la revisión puede plantearse bien sea ante el Registrador o ante el propio Director que ha de conocer de ella. (Art. 242). Contra la resolución que expida el Director cabe interponer recurso de apelación por ante la Junta de Vigilancia. Por último, agotado el procedimiento administrativo, es posible contradecir lo resuelto en esta vía, por ante el Poder Judicial. (Art. 247).

Contrariamente a lo que podría suponerse -dado que los Registradores son verdaderos jueces que examinan la legalidad de los títulos-. la inscripción no legitima el derecho que hace público. La publicidad entre nosotros no sanea el título, ni siquiera lo hace mejor. En otros términos, a pesar del examen de los títulos que realizan los Registradores, puede haber inscritos, y de hecho los hay, títulos nulos o anulables. Āsí lo prevee el artículo 1051 del Código Civil, que establece el procedimiento a seguir en el caso de inscripciones nulas o erróneas. Es éste uno de los grandes defectos de nuestro sistema registral. La inscripción no es entre nosotros prueba del derecho. Es, simplemente, una garantía para el ter- 
cero, conforme hemos de ver más adelante. Pero en cuanio al título mismo, es decir al derecho que se publica, en nada lo mejora.

f) Publicidad adjetiva.-Dijimos en el Título Primero de estos apuntes que la publicidad adopta una doble forma: la sustancia, con sus dos efectos principales, la legitimación y la fe pública; y la adjetiva, que es el medio a través del cual se realiza esa publicidad, es decir la forma como se conoce el contenido de los libros. Nos corresponde examinar las dos formas de esta publicidad adjetiva: el examen de los libros y la expedición de certificados.

1) Examen de los libros.-Cualquier persona, sin necesidad de que acredite el interés que pudiera tener, puede examinar los libros, ya sea los de fincas o los indices. La única limitación que existe al respecto es el pago de los derechos correspondientes.

2) Expedición de centificados.-El Registro expide dos clases de certificados: literales y compendiosos. Los primeros contienen una transcripción exacta del asiento o asientos solicitados. Los últimos contienen un extracto (art. 120).

Es importante consignar que los certificados sólo pueden expedirse a pedido de parte o mediando orden judicial (art. 114).

En cuanto al mérito probatorio de los certificados, es necesario recurir al artículo $126^{\circ}$ del Reglamento. Este dispositivo consagra una aberración. Dice el artículo en mención que cucndo exista disconformidad entre un certificado y el libro-disconformidad que surge como consecuencia de un error o de mala fe del Registrador que expide el certificado- deberá estarse a lo que resulte del libro. Decimos que la solución es equivocada porque importa negar todo mérito a los certificados. Supongamos, por ejemplo, que alguien nos ofrece un inmucble en garantía del cumplimiento de una obligación. Se trara de constituir una hipoteca sobre ese inmueble. Lo primero que hará el presunto acreedor hipotecario es pedir un certificado de gravómenes del bien que se le ofrece en garantía. Se le entrega un certificado reciente que acredita que la finca está realenga. Con esta seguridad, contrata $y$ se constituye el gravamen. Resulta que meses después aparece otro acreedor hipotecario, uno anterior que alega preferencia por la mayor antigüedad de su derecho real de garantía. Según el artículo en examen, este acreedor hipotecario es preferido al que contrató bajo la buena fe del certificado erróneo. Esta solución nos lleva a negar todo mérito a los certificados. Será necesario, en todo caso, el exámen directo de los libros para comprobar si el certificado expedido es o no conforme...

El Registro en el Perú defiende únicamente al tercero contratante bajo la fe de lo que el Registro le dice. Pues bien, es a ese tercero, en cuyo beneficio existe y funciona la institución registral, que se está perjudicando con lo establecido en el artículo 126. No puede haber seguridad en la contratación sobre inmuebles si la institución llamada a otorgarla no concede crédito absoluto e irrestricto $\alpha$ los certificados que expide. 
g) Efectos de las inscripciones.-Dos son los artículos que de modo preferente deben examinarse en esta materia: el 1050 y el 1052 del Código Civil, en especial este último.

E1 1050 ha establecido un orden de preferencia. Aparentemente existe incompatibilidad entre este artículo y el 1047 que dispone que no puede inscribirse un título traslativo de dominio incompatible con otro ya inscrito, aunque sea de fecha anterior. En realidad no hay incompatibilidad. El artículo 1050 prevee la posibilidad de que se inscriban actos de diferente naturaleza sobre un mismo bien. Por ejemplo un embargo y una compraventa. Digamos que Juan era dueño de una finca. Mientras lo fue, Jorge se la embargó por una deuda determinada. Juan vendió a Manuel y llega el momento de oponer derechos. El actual dueño Manuel no podró oponer su derecho de propiedad al derecho del embargante Jorge porque la inscripción de éste es anterior.

El artículo 1052 es en verdad el eje de nuestra institución registral. Aún cuando el Profesor argentino Lafaille considera que este artículo 1052 de nuestro Código Civil no es prueba de derecho, ni siquiera una presunción de la existencia del mismo, creemos que cimenta sobre bases más o menos sólidas la publicidad sustantiva $y$ es en su virtud que el tercero de buena fe encuentra absolutamente garantido el derecho que adquiere bajo la fe del Registro.

Como se recordará, cuando examinamos la publicidad sustantiva dijimos que eran dos sus efectos principales: la legitimación y la fe pública del registro. Por esta última debe entenderse lo siguiente: quien adquirió de buena fe $y$ a título oneroso de quien en el Registro aparece como dueño, e inscribe el derecho adquirido, compró bien. Este principio está plenamente consagrado en el artículo 1052.

Los actos o contratos onerosos que se otorguen por quien en el Registro aparezca con derecho para ello, una vez inscritos, no se invalidarán aunque se anule el derecho del otorgante en virtud del título anterior no inscrito o de causas que no resulten claramente del mismo registro

Un ejemplo ayuda a comprender este crtículo. Juan es dueño de una finca y tiene inscrito su derecho en el Registro de la Propiedad. Se la vende (contrato oneroso) a Fernando y este inscribe la transferencia de propiedad. Resulta que dos o tres meses después aparece Ricardo, a quien Juan le vendió primero la misma finca, pero omitió inscribir su adquisición. Es éste el "título anterior no inscrito" a que refiere el artículo. En realidad poco vale en el orden real. No podrá reivindicar la cosa de Fernando. Lo más que podrá es exigir una indemnización de Juan.

Nótese que según el artículo 1052 se deben dar los siguientes requisitos para que el tercero quede amparado: a) que el otorgante aparezca en el Registro con derecho inscrito, b) que el acto o contrato en virtud del cual se tramite este derecho sea así mismo objeto de inscripción y c) que este acto haya sido a título oneroso.

Nuestra jurisprudencia ha considerado además en ciertos casos que debe añadirse el requisito de la buena fe del tercero adquirente, esto es su ignorancia de la invalidez del derecho que adquiere. Nos parece jus- 
tificada esta exigencia, si bien no debe pedirse del tercero que pruebe su buena fe -hecho éste difícil de probar- sino más bien que no deberá amparárselo en caso de quo se acredite su mala fe.

Resulta difícil de comprender la frase final del artículo: "de causas. que no resulten claramente del mismo registro". El tercero no se encuentra protegido si la nulidad del título que adquirió se produjo en virtud de causas que resultaban claramente del mismo registro. Supongamos que Juan es propietario de un inmueble que no está registrado. Como no tiene títulos, forma supletorios e inscribe su derecho de propiedad. De inmediato vende a Jorge, quien adquiere a título oneroso $y$ bajo la fe del Registro. Jorge inscribe su adquisición. Pedro aparece entonces e interpone demanda contra Jorge para reivindicar parte del bien, afirmando ser el verdadero propietario en razón de que los títulos supletorios adolecen de nulidad; pues él, siendo colindante, no tue citado en el proceso judicial, usurpándose así su derecho sobre parte del inmueble que ahora aparece registrado íntegramente a nombre de Juan y luego del comprador Jorge. Sólo podrá declararse fundada esta demanda si de los mismos asientos de dominio apareciera la causal de nulidad de los títulos supletorios. De lo contrario, Jorge gozaría de su condición de tercero adquiriente a título oneroso bajo la fe del Registro y por tanto protegido contra la evicción. 